\title{
AS NOVAS VERTENTES DA MEDIAÇÃO E DA JUSTIÇA RESTAURATIVA. O NECRIM.
}

\author{
Cyntia Cardoso Santos, Pablo Rodrigo França \\ Universidade do Oeste Paulista - UNOESTE, curso de Direito, Presidente Prudente, SP. E-mail: \\ cyntia_ssantos@hotmail.com
}

\section{RESUMO}

O objetivo deste ensaio é introduzir, mesmo que brevemente, o estudo da mediação criminal como forma alternativa de resolução de conflitos de menor lesividade, trazendo para as partes uma resposta rápida e eficaz da Justiça Pública, não apenas resolvendo essas lides, mas, essencialmente restaurando as relações afetadas. Além, exaltar o eficiente trabalho do Delegado de Polícia, como técnico mediador, realizado no Núcleo Especial Criminal (Necrim), modelo de gestão já implantado pela Polícia Civil Paulista. Neste sentido, houve a importante abordagem teórica sobre a Justiça Restaurativa que busca justamente essa relação harmônica entre o autor e vítima, aperfeiçoando a cidadania de todas as partes que são convocadas a decisão em corresponsabilidade. Nada obstante, sem o abandono ao considerado processo penal tradicional que continuará como o amargo remédio aos delitos mais graves na busca da proteção da sociedade, aplicando estritamente o preceito da igualdade, na abordagem desigual as situações de periculosidade divergente.

Palavras-chave: Mediação Penal, Necrim, Justiça Restaurativa, Cidadania.

\section{THE NEW ASPECTS OF MEDIATION AND RESTORATIVE JUSTICE. THE NECRIM.}

\section{ABSTRACT}

The purpose of this essay is to introduce, even briefly, the study of criminal mediation as an alternative way of resolving less lenient conflicts, bringing to the parties a rapid and effective response from the Public Justice, not only by resolving these disputes, but essentially by restoring The relationships affected. In addition, to exalt the efficient work of the Police Delegate, as mediator technician, carried out in the Special Criminal Nucleus (Necrim), a management model already implemented by the Paulista Civil Police. In this sense, there was the important theoretical approach on restorative justice that seeks precisely this harmonious relationship between the author and victim, improving the citizenship of all parties that are called the decision in coresponsibility. However, without abandoning the traditional criminal procedure that will continue as the bitter remedy for the most serious crimes in the search for protection of society, strictly applying the precept of equality, in the unequal approach of situations of divergent danger.

Keywords: Criminal Mediation, Necrim, Restorative Justice, Citizenship.

\section{INTRODUÇÃO}

Nos últimos tempos, diversos países se preocuparam em separar procedimentalmente os crimes de maior e de menor potencial ofensivo, atribuindo a cada qual tratamento diferenciado em busca de uma justiça equilibrada. Para tal, alguns países substituíram o principio da obrigatoriedade pelo da oportunidade da ação penal. No Brasil foi introduzida em seu ordenamento a possibilidade de soluções consensuais para crimes de menor potencial ofensivo, amenizando a rigidez do princípio da obrigatoriedade, sem que haja necessário a instauração de uma ação penal (BLAZECK, 2013). 
Partilhando ao entendimento do referido autor, há a necessidade de diminuir a imposição estatal em relação ao princípio da obrigatoriedade, haja vista que devem ser confiadas as partes a escolha ou não para o ingresso de uma ação penal, independentemente do direito de se consumar a pacificação de seu conflito.

Neste sentido, salienta Penteado Filho (2013, p. 233) que "com a estruturação do Estado se estabelece a ordem jurídica, harmonizando as relações sociais intersubjetivas a fim de alcançar o bem comum e de atenuar os sacrifícios dos anseios individuais".

O estudo teve por objetivo refletir sobre a eficácia prática, além das consequências sociais e coletivas, da mediação e da justiça restaurativa na seara penal, onde a importância reflete na discussão acadêmica de uma temática que suscita aprofundamento e, consequentemente, possíveis soluções concretas, visando minimizar o número de ações penais que aglomeram a Justiça Pública, da mesma forma que eleva a pacificação através da transformação comunitária que se inicia na relação corresponsável das partes que são restauradas.

A sociedade, de maneira geral, carece de soluções práticas para vários problemas sociais existentes, dentre eles a própria eficácia do Poder Judiciário extremamente assoberbado diante de uma mesma sociedade litigante e que aposta tudo na decisão do juiz imparcial. Contudo, a demora e burocracia frustra qualquer das partes, mesmo entre os vencedores que, distantemente, possuem a recuperação do mal estar ocasionados pela peleja judicial.

Assim, o presente trabalho é de extrema importância, com o objetivo ousado em aguçar a discussão de acadêmicos quanto ao tema, propiciando novos entendimentos e questionamentos sobre estes, para que a partir dai todos possam exercer a sua opinião crítica a respeito do assunto apresentado, acarretando novos apontamentos no âmbito da pesquisa, buscando colocações sensatas e aperfeiçoando aos modelos e projetos já implementados, em homenagem a paz pública, segurança, aos direitos humanitários e ao aperfeiçoamento da cidadania.

\section{METODOLOGIA}

O presente trabalho será desenvolvido por meio de pesquisas bibliográficas, jurisprudências e artigos científicos, aproveitando da experiência empírica do trabalho dos autores, seja na dedicação as ações de segurança pública, seja na prática desenvolvida no estágio junto ao Núcleo Especial Criminal (Necrim), com aplicação principal do método hipotéticodedutivo.

Buscar-se-á uma discussão da realidade, descrevendo os paradigmas e propondo a quebra da rotina em benefício coletivo, partindo do raciocínio lógico geral para o particular. Todos os dados coletados serão discutidos, confrontados e argumentados dialeticamente.

\section{RESULTADOS}

Contemporaneamente, se fala muito em crise do poder judiciário, referindo a demora das sentenças, situação de difícil enfrentamento. Em verdade, depois dos tempos negros da antidemocracia, houve um apego exacerbado ao judiciário que acabou se confundido como sinônimo de decisão democrática ou de justiça. Quanto maior as sociedades há natural aumento dos conflitos sociais e, não diferente, elevam-se o numero de processo, inclusive criminais, o que causa grande dispêndio e longo período para que a lide possa ser solucionada em sentenças distantes das consequências práticas.

Em contrapartida, tona-se difícil aceitar que um cidadão que tenha atentado contra qualquer bem jurídico protegido não possa exigir uma prestação estatal, aceitando a impunidade que, não raras vezes, vem sob o manto do tempo percorrido sem a sentença, trazendo a população grave insegurança jurídica e motivando novas infrações. 
Das necessidades aqui resumidas surgiu à ideia de Justiça Restaurativa ou mediação também na seara penal, conforme traçada por Junior e Agostini (2013, p. 22):

A Justiça Restaurativa desloca a poder de decisão do Juiz para os protagonistas do conflito, preconizando que somente a punição do ofensor não restaura o trauma sofrido pela vítima. Objetiva construir a paz, assumindo que as situações de conflitos fazem parte da natureza humana e, portanto, necessitam de mecanismo de diálogo e participação de todos os envolvidos na busca da melhor solução possível.

Assim, podemos chegar à conclusão de que a Justiça Restaurativa não é apenas uma forma de impedir a violação de um bem jurídico tutelado, servindo também, como impedimento de uma possível violação das relações humanas (JUNIOR e AGOSTINI, 2013). É a preocupação com a consequência da decisão, ou seja, o efeito perante a coletividade, não reluzindo sobre culpados, mas, absorvendo o fato cometido e convidando as partes à corresponsabilidade para, juntos, chegarem a melhor decisão que será homologada, restaurando aquele conflito de pequena lesividade (exemplo, perturbação à tranquilidade entre vizinhos onde a demora de decisão do Estado poderia levar a ameaças, agressões ou até mesmo atentado contra a vida, enquanto que com a mediação será definida rapidamente e as partes voltam a se respeitar), transformando a comunidade, afastando as novas ações e crimes graves, bem como diminuindo o número de processos judiciais que continuarão dedicados aos fatos complexos.

Os resultados destacados já são realidade comprovada através dos inúmeros Núcleos Especiais Criminais (Necrim's) espalhados pelo Estado, projeto da Polícia Civil paulista em que a média de acordos homologados e relações restauradas superam os $90 \%$, ou seja, minimamente a cada 1.000 (mil) conflitos sociais, apenas e no máximo 100 tornam-se processos judiciais, ou seja, mais de 900 são resolvidos rapidamente e com absoluto cuidado da relação restaurada, garantindo os clamados direitos humanistas e, notadamente, desburocratizando a Justiça Pública e lapidando a cidadania.

\section{DISCUSSÃO}

Como ponto de partida, e em outras palavras, citamos o asseverado na "Magna Carta" quando, entre centenas de direitos (a maioria direitos fundamentais), elenca o de receber do Estado uma solução rápida as lides enfrentadas ou conquistadas no cotidiano.

Ainda, percebemos o artigo 98, inciso I da mesma Carta Maior, que trás em seu bojo a previsão para a criação de juizados especiais e que recebe uma melhor regulamentação com a Lei no 9.099/95, também se preocupa com esse resultado célere.

Desta feita e em mesma sintonia, com a necessidade de evolução nos procedimentos estatais, mais uma vez, exaltamos a forma alternativa de solucionar conflitos, com a mediação, com embrião implantado na cidade de Bauru, interior do Estado de São Paulo, sob a denominação NECRIM (Núcleo Especial Criminal).

O NECRIM se tornou um órgão especializado da Policia Civil paulista e criado para desempenhar a pacificação social já na fase administrativa, trazendo celeridade à solução dos conflitos de interesses, onde o Delegado de Policia desempenha a função de mediador nos crimes de menor potencial ofensivo, conforme leciona na ideia Luiz Mauricio Souza Blazeck (2013, p. 157).

Em consonância com a sua função e necessidade, devemos notar que grande parte das relações sociais são regulamentadas por princípios, conquistas trazida ao longo do tempo por tratados internacionais ratificados por nosso País. A Carta vigente da República permite com a redação do citado artigo 98 , inciso I, que as lides sejam resolvidas de formas alternativas, trazendo 
mais rapidez e segurança jurídica àquele que procura solução para seus conflitos. Regulamentado pelos princípios da celeridade, oralidade e da economia processual, além do principio/direito ao acesso a justiça (que não se confunde necessariamente com o Poder Judiciário).

Sinoticamente, segundo o principio da celeridade processual o processo deve correr em um curto lapso temporal, necessário para atender os anseios das partes conflitantes. O principio da oralidade traz em seu bojo a chance das partes conversarem, dialogarem para chegarem a uma solução. Quando falamos em economia processual, faz-se ligação direta com a celeridade e baixos custos ao erário, pois, quanto mais rápido o processo menos gastos sofrerão, e por fim, o principio do acesso à justiça, em que todo cidadão goza do direito de acionar o poder judiciário ou os órgãos competentes para ver suas pretensões conquistadas, ou, como entendemos, subsidiariamente todos têm o direito de acionar o poder judiciário caso não tenham do Estado à solução pacífica de seu litígio, mesmo que de maneira administrativa.

Conforme referido na doutrina de Thais Pandolfi (2014) realmente há, ainda, algum receio de parte dos órgãos da persecução em absorver a novidade anunciada com o temor da ausência de imparcialidade nas citadas audiências. O que, com reverência, os resultados alcançados rechaçaram.

Vale distinguir neste momento, por importante, a diferença essencial entre mediação e conciliação. A primeira se trata de uma autocomposição, sem qualquer exigência do mediador que simplesmente facilita o entendimento entre as partes (apresentando os fatos e consequências), não interferindo em suas vontades em momento algum. Diametralmente oposta, na segunda, o conciliador apresenta aos litigantes um tipo de acordo, já desenhado, cabendo a estes aceitarem ou não, sendo certo que neste momento, o conciliador interfere no desejo das partes, não ficando inerte (FILHO, 2013, p. 234-235).

Juízes e delegados são grandes figuras sociais com diferentes funções. Quando pensamos na autoridade do magistrado lembramo-nos de uma autoridade quase intocável, realizando um contato rápido com as partes (na audiência) e a partir deste tomar decisões. Já quando refletimos sobre o Delegado de Policia, pensamos na primeira autoridade contatada para expressar os anseios, as indignações, o desejo de resolver pacifica e prontamente algum conflito. Nesta toada às palavras de Blazeck (2013, p. 155).

O papel do Delegado de Policia será de conscientizar as partes de que as melhores soluções para os problemas não estão nos extremos, mas sempre no meio, ensinando-as a divergirem sem perder o respeito e a importância de aprenderem a lidar com as renuncias e frustrações da vida, de forma que os litigantes voltem a conviver em harmonia social, reduzindo a possibilidade eclosão de um novo conflito, ou seja, evitando a reincidência.

Na prática, os crimes de menor potencial ofensivo dão ensejo ao procedimento chamado Termo Circunstanciado (TC). O Delegado de Policia, no Necrim, notifica as partes para audiência com natureza de Mediação e estas podem estar acompanhadas por advogados regularmente constituídos. Durante a audiência será lavrado o Termo de Composição Preliminar que será anexo ao procedimento e encaminhado ao Poder Judiciário, surtindo total eficácia apenas após a homologação judicial. Com o exposto acima, nota-se que não há qualquer usurpação de função ou ato de jurisdição, pois, o Delegado de Policia atua como simples e eficiente pacificador social.

Como já explanado, o escopo do NECRIM e da própria mediação é a diminuição da reincidência, o aumento da pacificação social, valorização da imagem do órgão da segurança de repressão e uma maior garantia aos princípios constitucionais, através da restauração das relações. Neste ato, segue nas palavras de Blazeck (2013, P.173): 
Finalmente, é inegável afirmar que o NECRIM tornar-se-á instrumento restaurador e fortalecedor da imagem e da identidade institucional, considerando as praticas mediadoras e conciliatórias na solução dos conflitos, promovendo a reaproximação da sociedade, resgatando a confiança e credibilidade, auxiliando a Policia Civil na realização de suas atribuições de polícia judiciária pacificadora no sistema de justiça criminal do Brasil.

Por fim, o objeto da mediação penal não é o crime em si, como algo que deve ser severamente punido, como um fato bruto que causa impugnação social, nem mesmo o delinquente em si, o foco principal da justiça restaurativa está ligado às consequências dos crimes e nas relações sociais que por ele são afetadas (PRUDENTE e SABADELL, 2014).

\section{CONCLUSÃO}

O processo penal e os seus instrumentos de persecução devem acompanhar a evolução dos tempos, seja na criação de novas ferramentas, seja na técnica de hermenêutica aplicada. Ainda, o direito a pacificação dos conflitos e a celeridade das decisões estão umbilicalmente ligados a esta assertiva.

Nota-se mais uma vez que, além da desburocratização ou litigiosidade excessiva que assoberbam a atuação do Poder Judiciário, esse foi o mote da Constituição Federal em permitir, entre tantos outros mecanismos, a criação de Juizados Especiais com o desejo da almejada eficácia e rapidez na resolução de conflitos. O surgimento do NECRIM segue o mesmo objetivo ao utilizar a prática da mediação, com excepcionais consequências ao restaurar os vínculos entre as partes conflitantes e inibindo reincidências ou a necessidade de um possível encarceramento.

É necessário uma visão ética em relação aos conflitos e os anseios sociais, importando-se mais com os motivos que levaram a causa litigiosa e menos com o apontamento de culpados. Mais com a pacificação espontânea e com a restauração das relações e menos com a segregação social. Assim, o diálogo e compaixão, associados ao desbaste da cidadania, prevalecerão.

\section{REFERÊNCIAS}

BLAZECK, Luiz Mauricio Souza. O Delegado Como Mediador de Conflitos. In: BLAZECK, Luiz Mauricio Souza e MARZAGÃO Jr, Laerte I. Mediação- Medidas Alternativas Para Resolução de Conflitos Criminais. São Paulo: Quartier Latin, 2013.

BLAZECK, Luiz Mauricio Souza e MARZAGÃO Jr, Laerte I. Mediação- Medidas Alternativas Para Resolução de Conflitos Criminais. São Paulo: Quartier Latin, 2013.

BRASIL. Constituição (1988). Constituição da República Federativa do Brasil. Promulgada em 5 de outubro de 1988. Disponível em: <http://www.planalto.gov.br/ccivil_03/constituicao/constituicaocompilado.htm.>. Acesso em 08 de agosto de 2017.

JUNIOR, Arnaldo Hossepian Salles; AGOSTINI, Alexandra Comar. Presecução Penal- A Justiça Restaurativa Como Forma de Solução de Conflitos Decorrente de Pratica de Crime. In: BLAZECK, Luiz Mauricio Souza e MARZAGÃO Jr, Laerte I. Mediação- Medidas Alternativas Para Resolução de Conflitos Criminais. São Paulo: Quartier Latin, 2013. 
MARZAGÃO Jr., Laerte I. O Delegado de Policia Conciliador. In: BLAZECK, Luiz Mauricio Souza e MARZAGÃO Jr, Laerte I. Mediação- Medidas Alternativas Para Resolução de Conflitos Criminais. São Paulo: Quartier Latin, 2013.

PENTEAdO FILHO, Nestor Sampaio. Poder de Polícia Mediação de Conflitos. In: BLAZECK, Luiz Mauricio Souza e MARZAGÃO Jr, Laerte I. Mediação- Medidas Alternativas Para Resolução de Conflitos Criminais. São Paulo: Quartier Latin, 2013.

PANDOLFI, Thais. A Atuação no NECRIM na fase Pré-Processual e a Lei 9.099/95 no Procedimento Sumaríssimo. 2014. Disponível em: < https://thaispandolfi.jusbrasil.com.br/> Acesso em 29 mar. 2017.

SABADELL, Ana Lucia; PRUDENTE, Neemias Moretti. Mudança de Paradigma: Justiça Restaurativa. Disponível em: <http://justificando.cartacapital.com.br/2014/08/29/mudanca-de-paradigmajustica-restaurativa/> Acesso em 03 mar. 2017.

SILINGOVSHI, R. R. L (coord.)et al. normas e padrões para trabalhos acadêmicos e científicos da Unoeste. 3. ed. Presidente Prudente: Universidade do Oeste Paulista, 2015. Disponível em: < http://www.unoeste.br/site/biblioteca/documentos/Manual-Normalizacao.pdf?v=6 >. Acesso em: 31 maio.2017. 